inch in diameter. The throwsters, that is, the operators who twist silk fibres into raw silk or raw silk into thread, find that they can work much better and much more quickly when the threads are brilliantly illuminated by the light from electric discharge lamps. To avoid eye strain, the Factories Act which came into force in July 1938 has emphasized the necessity for adequate lighting in such cases. We learn from an article on factory lighting which appeared in the Electrician of March 24, that G. H. Heath and Co. of Macclesfield and an associated company, British Crepe, Ltd., said to be the largest firm of silk throwsters in Great Britain, after experimenting with many kinds of lighting, have recently adopted as standard throughout their factories the electric discharge lamps made by Siemens Electric Lamps and Supplies, Ltd., with very successful results. In one case a room at the factory was lighted by discharge lamps consuming a total of $4.7 \mathrm{kw}$. and giving approximately 13-15 foot candles, whereas with gas-filled electric lamps the same room would have required $14.5 \mathrm{kw}$., that is, more than three times as much, and would only have given a lighting intensity of 7-8 foot candles. The sizes of the Siemens "QH" lamps installed are $80 \mathrm{w}$. and $125 \mathrm{w}$., according to the size and height of the rooms. The economy effected in running costs is very noticeable.

\section{Compulsory Illumination in Factories}

IN a special leaflet (Form 282) dated March 1939, the Factory Department of the Home Office reminds the owners of factories that the Departmental Committee appointed to deal with the subject has issued its fourth report (H.M. Stationery Office. 1s. 1d.) It recommends certain minimum standards of illumination below which work in factories should not be done regularly, and further recommends that these standards should be made legally compulsory next July. Tables of lighting practice suitable for many industrial processes can be obtained from the Illuminating Engineering Society, 32 Victoria Street, S.W.1. Another similar table is issued by the Electric Lamp Manufacturers Association, at Savoy Hill, W.C.1. The Secretary of State directs attention to a memorandum of the Air Raid Precautions Department, dealing with a general scheme of lighting restrictions to be enforced in the event of war. Occupiers of factories are recommended to obtain and study this memorandum, but naturally it deals more particularly with the screening of windows and roof lights in order to prevent the emission of light from buildings. It is in no way inconsistent with the requirement of adequate and suitable lighting within the building. Information and advice on general lines are usually obtainable from the gas or electricity undertaking supplying the factory.

\section{Progress in Horticultural Science}

VoL. 7 of Scientific Horticulture, the journal of the Horticultural Education Association (from the Hon. Editor, Mr. R. T. Pearl, S.E. Agric. Coll., Wye, Kent. $4 s$. net.; $4 s$. $6 d$. by post, February 1939) contains a well-balanced collection of papers for gardeners, both practical and professional. There are papers upon commercial horticulture in Eire, Devon, Lancashire and Bedfordshire, and articles upon the practical control of slugs by the use of 'Meta fuel', by S. G. Jary, and the horticultural work of the Land Settlement Association, by $\mathrm{H}$. Fairbank. Messrs. H. G. H. Kearns and H. Martin contribute an account of the physical properties and practical use of combined insecticidal and fungicidal washes for use upon expanded blossom and foliage. They conclude that oil emulsions afford the most promising basis for combined direct and protective sprays, and practical instructions are given for their use upon various tree fruits and soft fruits. Interesting possibilities of the controlled nutrition of horticultural crops by growth in nutrient solutions are envisaged by Messrs. S. R. Mullard and R. H. Stoughton. Though the huge increases in yield claimed for the method in California were not realized in England, growth of gladioli was superior to that from soil-grown corms. Lela V. Barton summarizes the work of the Boyce-Thompson Institute, New York, upon germination and dormancy in seeds. Effective pre-treatments for dormant seeds and for the after-ripening of certain species, are condensed into three tables of great practical utility. Epicotyl dormancy, where the radicle begins growth but not the plumule, can be broken by keeping rooted seeds at a cool temperature, usually between $40^{\circ}$ and $50^{\circ} \mathrm{F}$. for a few weeks. A series of papers by members of the staff of the East Malling Research Station, on the occasion of the Association's annual conference in September 1938, is also included in the volume.

\section{Radio Meteorology in the United States}

THE growth of aviation has resulted in an urgent and intensive demand for accurate weather forecasting not only at ground-level but also at all heights now utilized by aircraft. Methods previously employed for determining aerological data in the atmosphere have utilized kites, sounding balloons or aeroplanes to carry special instruments recording the temperature, pressure and humidity at various altitudes. A mimeographed report entitled "The Radio-Telemeter and its Importance to Aviation", by R. W. Knight, has recently been cireulated by the U.S. Civil Aeronautics Authority. This report discusses the general problem of determining aerological data by radiosounding balloons, to which are attached transmitters emitting signals carrying the indications of the meteorological instruments. A somewhat detailed description is then given of the apparatus developed for this purpose by the Blue Hill Observatory of Harvard University. Illustrations are given of the complete radio transmitter, with the associated instruments for determining temperature, pressure and humidity. At the ground station, the signals are received on a simple pen-writing recorder, from which the aerological information can be observed while the balloon flight is in progress. A specimen record indicates that heights up to $72,000 \mathrm{ft}$. (14 miles) can be obtained by this type of apparatus. The U.S. 